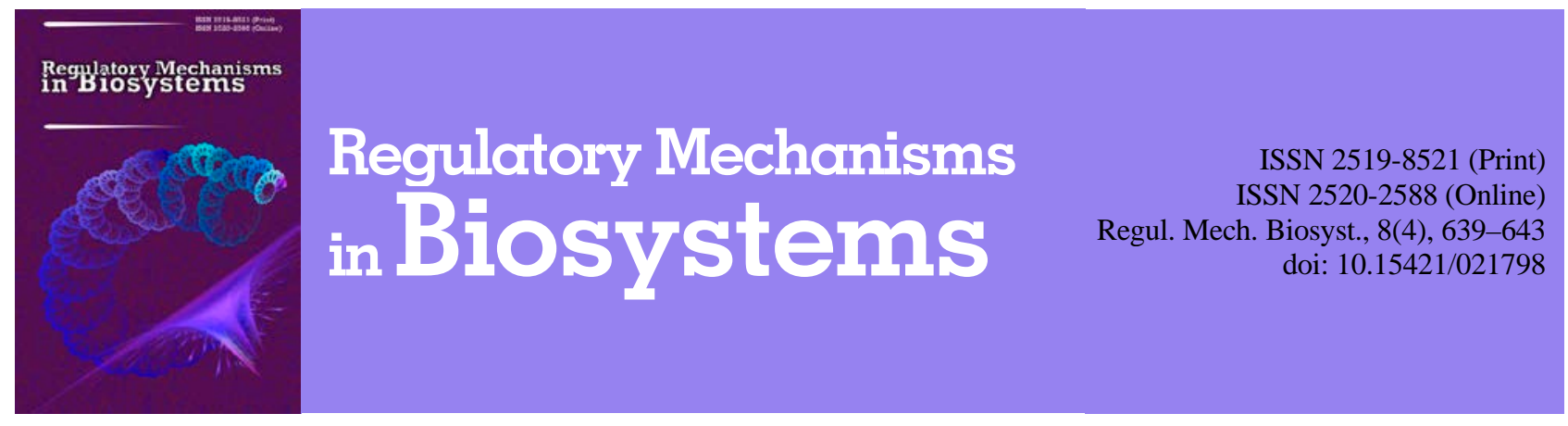

\title{
Morphofunctional indicators demonstrated by young students resident in Russia's Northeast
}

\author{
I. V. Averyanova, A. L. Maksimov, S. I. Vdovenko \\ Scientiic Research Center "Arktika”, Fareastern Branch of the Russian Academy of Sciences, Russia
}

Article info

Received 06.10.2017

Received in revised form 14.11.2017

Accepted 16.11.2017

Scientiic Research Center "Arktika", Fareastern Branch of the Russian Academy of Sciences (SRC “Arktika” FEB RAS) Russia.

Tel.: 4132-62-84-82. E-mail: Inessa1382@mail.ru
Averyanova, I. V., Maksimov, A. L., \& Vdovenko, S. I. (2017). Morphofunctional indicators demonstrated by young students resident in Russia's Northeast. Regulatory Mechanisms in Biosystems, 8(4), 639-643. doi:10.15421/021798

The specific climatic and geographical conditions of the northern territories of Russia, the relatively small workforce, as well as intensive migration processes require a specific approach with regard to northern regions and, particularly, to the healthcare of the young generation residing in the territory. This study was aimed at exploring the body functionality of the young inhabitants of Russia's Northeast considered as a human rescource for the future in relation to their period of residence in Magadan oblast. Based on the study of cardiovascular, biochemical, lipid and carbohydrate metabolism, psychophysiological characteristics, as well as respiratory system and gas exchange parameters, a comparative examination was carried which involved 1,560 male students aged 17-21. Depending on their period of residence in Magadan oblast, the examined subjects were divided into three groups. Group 1 was presented by newcoming settlers, whites by origin (adaptants), who had migrated from the Central-European or Asian areas of Russia and lived in the northern region for at least 5 years (the zero generation). Group 2 was made up of those young males born and living in Magadan oblast (the 1st generation), whites by origin, who were children of immigrants to the area. Finally, group 3 was representatives of the 2nd generation born and living in Magadan oblast, whose parents were representatives of the 1st generation. We found that people with a longer term of residency in the north had become more optimized in cardiovascular functioning (demonstrate decrease in arterial pressure and more effective myocardial performance), less stressed in external respiration with simultaneous decrease in exhaled heat loss, had normalised lipid metabolism shown through a reduced percentage of deviations in lipidograms as well as the index of atherogenicity and higher functioning of the central nervous system. Besides, having experienced severe climatic conditions they have formed their specific region-related metabolic profile featuring lowered lipid metabolism values and high blood glucose which can be caused by changes in nutrition of city residents. It should be concluded that discovered tendency of adaptive changes demonstrated by north-born young white males enables us to consider it as formation of a new population of inhabitants of the North having the best functional abilities for optimal adaptation to the specific ecological and climatic conditions.

Keywords: young males; cardiovascular system; external breathing function indices; psychophysiological characteristics; physiological systems; biochemical profile

\section{Особенности морфофункциональных показателей юношей-студентов, постоянных жителей Северо-Востока России}

\author{
И. В. Аверьянова, А. Л. Максимов, С. И. Вдовенко
}

Федеральное государственное бюджетное учреждение науки Научно-исследовательский центр «Арктика» Дальневосточного отделения Российской академии наук, Россия

Особые климато-географические условия северных территорий России, относительно низкая численность производственных сил, а также интенсивные миграционные процессы требуют применения особого подхода в отношении территорий Севера, наиболее важным звеном которой должно стать сохранение здоровья подрастающего контингента. Целью данной работы явилось изучение функционального состояния организма молодых жителей как основы будущего человеческого ресурса Северо-Востока России в зависимости от продолжительности проживания на территории Магаданской области. На основании изучения показателей сердечно-сосудистой системы, липидного и углеводного обмена биохимического профиля, психофизиологических характеристик, респираторной системы и газообмена проведено сравнительное изучение 1560 юношей-студентов возрастом 17-21 год. Обследуемый контингент в зависимости от сроков проживания на территории Магаданской области был поделен на три группы. Первую группу представили приезжие мигранты из числа европеоидов (адаптанты) из центрально-европейских и азиатских районов России со стажем пребывания в северных районах не менее пяти лет (нулевое поколение). Во вторую группу вошли юноши - уроженцы Магаданской области в первом поколении, уроженцы Магаданской области из 
числа европеоидов, у которых родители являлись мигрантами, и третью группы составили представители второго поколения - уроженцы Магаданской области, у которых родители являлись представителями первого поколения. Результаты исследования показали, что у лиц с наибольшим стажем проживания в условиях Севера происходит оптимизация в работе сердечно-сосудистой системы (снижение артериального давления и повышение эффективности работы миокарда), снижение напряжения в работе внешнего дыхания при одновременном уменьшении респираторных теплопотерь, нормализация липидного обмена за счет снижения процента отклонений в липидограммах и индекса атерогенности, а также возрастает функциональный уровень центральной нервной системы. Также в процессе проживания в сложных климатических условиях у них происходит формирование особенного регионального состояния метаболического профиля, характеризующегося сниженными концентрациями показателей липидного обмена и повышенным содержанием глюкозы в крови, что, по-видимому, связано с изменением питания современного городского жителя. В заключение необходимо отметить, что выявленная направленность адаптационных перестроек у молодых уроженцев-северян из числа европеоидов позволяет рассматривать это в качестве процесса формирования новой популяции жителей территории Севера, имеющей наибольшие функциональные резервы с точки зрения достижения максимальной адаптации к особенным эколого-климатическим условиям.

Ключевые слова: юноши; сердечно-сосудистая система; показатели газоанализа; функции внешнего дыхания; психофизиологические характеристики; биохимический профиль

\section{Введение}

Крайний Север, а также приравненные к нему территории представляют собой обширные районы, которые занимают существенную часть территории России, при этом значительная часть Востока страны характеризуется суровым климатом. В данных областях «высоких широт» формируется особая климато-экологическая обстановка, характеризующаяся низкой среднегодовой температурой, относительно жестким ветровым режимом, преобладанием снежного покрова, сменами полярной ночи и дня, а также высокой активностью гелиокосмических факторов, частыми возмущениями в ионосфере и, как следствие, высокой ионизацией воздуха, напряженностью магнитного поля - tension (Lasker, 1969; Soulman et al., 1980; Osterman et al., 1981). Среди всех субъектов Российской Федерации по численности проживающих Магаданская область занимает предпоследнее, 81-е, место после Чукотки и 11-е место по занимаемой площади (Shershakova, 2013). По данным Shershakova (2013), Магаданская область по сравнению с другими регионами страны территориально расположена в наиболее неблагоприятных условиях (Shershakova, 2013).

Абиотические факторы внешней среды вызывают соответствующие реакции ряда физиологических механизмов, направленных на сохранение целостности организма. Указанные отличительные особенности северных территорий определяют сложность пребывания человека в данных условиях. Непривлекательность суровых северных условий, а также продолжающийся миграционный отток населения осложняют создание и развитие человеческого капитала области. Освоение районов Крайнего Севера, а также приравненных к ним территорий, каковой и является Магаданская область, в данный момент идет в основном за счет процесса миграции населения из регионов, сильно отличающихся по своим климато-географическим параметрам. Наблюдаемый интенсивный отток молодежи из области указывает на то, что регион лишается своей будущей «северной» рабочей силы, так необходимой для успешного развития края. Обеспечить возможность полноценного и относительно комфортного существования человека в новых климатических и социальных условиях может лишь перестройка физиологических функций организма; в противном случае неизбежно ухудшение состояния здоровья и рост числа хронических болезней организма (Startseva et al., 2007; Kalichman et al., 2011; Khadilkar et al., 2015). Возрастающая разбалансированность средовых отношений в регионах Севера, неадекватная социальная цена и экологическая несбалансированность гипертрофированного роста ресурсных отраслей требует особого подхода региональной политики в отношении данных территорий, важнейшим звеном которой обязана стать охрана здоровья подрастающего контингента, основанная на принципах экологии, а также учете процессов адаптации и коррекции жизнедеятельности (Denisov et al., 2003).

Студенческая молодежь в данном аспекте привлекает особое внимание. Студенты являются не только мощными потенциальными трудовыми ресурсами общества, но и популяционным пулом, посредственное и откровенное плохое состояние

здоровья которого негативным образом скажется и на дальнейших поколениях (Irazusta et al., 2007).

В данной связи целью этой работы является изучение функционального состояния организма молодых жителей как основы будущего человеческого ресурса Северо-Востока России с учетом времени проживания на данной территории.

\section{Материал и методы исследований}

При помощи методики случайной выборки было обследовано 1560 юношей в возрастном периоде 17-21 год, живущих на постоянной основе в регионе. Данные люди были поделены на три подгруппы. В первую (56 человек) входили приезжие мигранты из числа европеоидов (адаптанты) из центральноевропейских и азиатских районов России со стажем пребывания в северных районах не менее 5 лет (в среднем 7,2 $\pm 1,4$ лет), т. н. нулевое поколение. Вторая группа - это юноши-уроженцы Магаданской области в первом поколении из числа европеоидов (924 человека), третья группа - представители второго поколения (580 человек), при этом у обеих данных групп родители являлись мигрантами-адаптантами, приехавшими на Северо-Восток в прошлом веке.

Для анализа состояния системы кровообращения с помощью тонометра-автомата Nessei DS-186 (Япония) в покое проводили измерение значений систолического (САД, мм рт. ст.) и диастолического (ДАД, мм рт. ст.) артериального давления, а также частоты сердечных сокращений (ЧСС, уд./мин). Общее периферическое сопротивление сосудистого определялось расчетным путем (ОПС, дин. с. см $\left.{ }^{-5}\right)$, так же как и ударный объем по Starr (УО, мл) (Yurev et al., 2003).

Для газового анализа, а также оценки респираторной системы при помощи метаболографа MedGraphics VO2000 (США) также в состоянии покоя определялся минутный объем дыхания (МОД, л), дыхательный объем (ДО, мЛ), коэффициент использования кислорода $\left(\mathrm{KИО}_{2}\right.$, мл/л). Ряд других показателей респираторной системы фиксировался при помощи компьютерного спироанализатора КМ АР-01 Диамант-С (Россия). Все базовые показатели сравнивали с должными значениями, являющимися инвариантами нормы, полученными в отношении жителей Центрально-Европейской России. Анализ состояния респираторной системы осуществляли на основании оценки объемных и объемно-скоростных значений легких: ЖЕЛ - жизненная емкость легких (\%), ПОС пиковая объемная скорость выдоха (\%), $\mathrm{MOC}_{25 \%}, \mathrm{MOC}_{50 \%}$ и $\mathrm{MOC}_{75 \%}$ - мгновенные объемные скорости на участках $25 \%, 50 \%$ и $75 \%$ от объема форсированного выдоха, соответственно, (\%). С помощью психофизиологической системы контроля уровня стресса FirstSync (СКУС, Россия) определяли скорость простой, а также сложной зрительно-моторной реакции (ПЗМР, СЗМР, мс). Для анализа функциональных возможностей газотранспортной и респираторной систем методом неинвазивной фотооксигемометрии с помощью пульсоксиметра NPB 40 (США) во время максимальной задержки дыхания на вдохе и выдохе (проба Stange и Genchie) определяли сатурация гемоглобина кислородом $\left(\mathrm{HbO}_{2} \%\right)$.

Для оценки биохимического профиля в обследовании приняли участие 110 юношей. В группу мигрантов-европеоидов вошли 
20 испытуемых, в группу лиц первого поколения - 35, а выборку лиц второго поколения - 37 испытуемых. Определение общего холестерина (ОХЛ, ммоль/л), глюкозы (ммоль/л), триглицеридов (ТГ), липопротеидов высокой плотности (ХС ЛПВП, ммоль/л) и липопротеидов низкой плотности (ХС ЛПНП, ммоль/л) в капиллярной крови, взятой утром натощак, как минимум, через 10 часов после приема пищи, было проведено при помощи портативного биохимического экспресс-анализатора CardioChek PA (США). Коэффициент атерогенности (КА) рассчитывали по формуле:

$$
\text { КА }=(\text { ОХС-ХC ЛПВП }) / \text { ХС ЛПНП })
$$

Для оценки атерогенного потенциала липидов крови установлены следующие значения: показатель отношения липопротеидов низкой плотности к липопротеидам высокой плотности (ХС ЛПНП / $\mathrm{XC} \mathrm{ЛПВП)} \mathrm{и} \mathrm{отношение} \mathrm{липопротеидов} \mathrm{высокой} \mathrm{плотности} \mathrm{к}$ общему холестерину (ОХС / ХС ЛПВП) (Expert panel, 2001).

Все обследования осуществлялись в помещении с температурой окружающего воздуха $18-20{ }^{\circ} \mathrm{C}$, в первой половине дня. Исследования проведены в соответствии с Хельсинской декларацией. Алгоритм обследований одобрен Этическим комитетом медико-биологических исследований при СВНЦ ДВО РАН. Перед обследованием у каждого юноши получено письменное информированное согласие. Полученные данные обработаны с применением пакета Statistica 7.0. Проверка на нормальность распределения выборки, осуществленная при помощи теста Колмогорова - Смирнова, показала, что все данные являются нормально распределенными. Результаты представлены в виде среднего значения (х) и стандартной ошибки средней (SE). При обработке данных исполь- зовали дисперсионный анализ с последующим попарным сравнением при помощи критерия Sheffe. Критический уровень значимости (Р) принят равным 0,05 (Borovikov, 2003).

\section{Результаты}

Базовые физиологические показатели различных систем организма юношей из числа адаптантов Севера, которые являются представителями различных поколений, приведены в таблице. В отсутствии межгрупповых различий по пульсу, а также уровню сопротивления сосудов преобладает ясная тенденция, направленная на снижение уровня как систолического, так и диастолического АД от лиц из числа мигрантов-адаптантов (нулевое поколение) к лицам второго поколения в отсутствие значимых различий у юношей в первом и втором поколениях. Дыхательный объем имеет отчетливую тенденцию к уменьшению по мере возрастания срока адаптации. Подобная динамика выявлена и для параметра минутного объема, минимальные значения которого установлены у лиц второго поколения.

Респираторная система характеризуется преимущественным снижением объемно-скоростных значений от юношей нулевого и первого к юношам второго поколения. При неизменных значениях жизненной емкости легких и проводимости мельчайших и мелких бронхиол $\left(\mathrm{MOC}_{75 \%}\right)$, у лиц второго поколения выявляются минимальные показатели выдоха на пиковой скорости, а также проводимости бронхиол большого $\left(\mathrm{MOC}_{25 \%}\right)$ и среднего $\left(\mathrm{MOC}_{50 \%}\right)$ калибра.

Таблица

Сравнение различных физиологических систем организма юношей - представителей нулевого, первого и второго поколений

\begin{tabular}{|c|c|c|c|c|c|c|}
\hline \multirow[b]{2}{*}{ Наименование показателя } & \multicolumn{3}{|c|}{ Сравниваемые группы } & \multicolumn{3}{|c|}{ Значимые различия между группами, $\mathrm{P}$} \\
\hline & $\begin{array}{c}\text { нулевое поколение, } \\
n=56\end{array}$ & $\begin{array}{c}\text { первое поколение, } \\
\text { n = } 924\end{array}$ & $\begin{array}{c}\text { второе поколение, } \\
n=580\end{array}$ & $1-2$ & $2-3$ & $1-3$ \\
\hline САД, мм рт. ст. & $130,4 \pm 0,81$ & $128,4 \pm 0,42$ & $128,3 \pm 0,41$ & 0,03 & 0,87 & 0,02 \\
\hline ДАД, мм рт. ст. & $79,9 \pm 0,91$ & $77,0 \pm 0,31$ & $76,2 \pm 0,44$ & 0,01 & 0,62 & $4,7 * 10^{-4}$ \\
\hline ЧСС, уд. мин & $82,4 \pm 1,60$ & $82,9 \pm 0,51$ & $81,5 \pm 0,52$ & 0,98 & 0,94 & 0,98 \\
\hline УО, мЛ & $67,5 \pm 0,93$ & $69,4 \pm 0,37$ & $70,7 \pm 0,51$ & 0,57 & 0,41 & $3,2 * 10^{-3}$ \\
\hline ОПС, динсс $\mathrm{cm}^{-5}$ & $1498 \pm 43$ & $1446 \pm 14$ & $1443 \pm 16$ & 0,96 & 0,78 & 0,8 \\
\hline ДО, мл & $762 \pm 40$ & $672 \pm 14$ & $612 \pm 18$ & 0,04 & 0,01 & $1,3 * 10^{-3}$ \\
\hline МОД, л & $10,5 \pm 0,51$ & $9,4 \pm 0,21$ & $8,6 \pm 0,23$ & 0,04 & 0,01 & $1,4 * 10^{-3}$ \\
\hline $\mathrm{KИO}_{2}$, мл/л & $34,1 \pm 0,86$ & $36,3 \pm 0,42$ & $37,5 \pm 0,24$ & 0,01 & 0,01 & $2,1 * 10^{-4}$ \\
\hline ЖЕЛ, \% & $100 \pm 1,9$ & $102 \pm 0,9$ & $101 \pm 0,9$ & 0,43 & 0,39 & 0,72 \\
\hline ПОС, \% & $112 \pm 2,4$ & $111 \pm 1,1$ & $107 \pm 1,1$ & 0,71 & 0,01 & 0,05 \\
\hline $\mathrm{MOC}_{25 \%}, \%$ & $113 \pm 3,1$ & $110 \pm 1,2$ & $105 \pm 1,3$ & 0,36 & 0,01 & 0,05 \\
\hline $\mathrm{MOC}_{50 \%} \%$ & $117 \pm 3,5$ & $117 \pm 1,6$ & $111 \pm 1,9$ & 0,82 & 0,02 & 0,22 \\
\hline $\mathrm{MOC}_{75 \%} \%$ & $134 \pm 5,4$ & $142 \pm 2,6$ & $139 \pm 2,7$ & 0,25 & 0,42 & 0,53 \\
\hline ПЗМР, мс & $225 \pm 2,5$ & $215 \pm 1,4$ & $210 \pm 1,3$ & $3,7 * 10^{-4}$ & 0,01 & $5,3 * 10^{-8}$ \\
\hline С3MP, мс & $258 \pm 4,8$ & $260 \pm 1,2$ & $250 \pm 1,8$ & 0,65 & $4,3 * 10^{-6}$ & 0,13 \\
\hline Фоновый уровень $\mathrm{HbO}_{2}$, \% & $99,4 \pm 0,14$ & $99,2 \pm 0,01$ & $98,9 \pm 0,01$ & 0,05 & $4,1 * 10^{-5}$ & 0,01 \\
\hline Уровень $\mathrm{HbO}_{2}$ на пике пробы Штанге, \% & $97,2 \pm 0,51$ & $97,1 \pm 0,13$ & $97,2 \pm 0,12$ & 0,75 & 0,2 & 0,99 \\
\hline Уровень $\mathrm{HbO}_{2}$ на пике пробы Генчи, \% & $93,3 \pm 0,62$ & $94,8 \pm 0,11$ & $94,6 \pm 0,21$ & 0,01 & 0,4 & 0,05 \\
\hline ОХС, ммоль/л & $4,2 \pm 0,22$ & $3,5 \pm 0,12$ & $3,3 \pm 0,25$ & $2,3 * 10^{-3}$ & 0,32 & $1,5 * 10^{-3}$ \\
\hline ТГ, моль/л & $0,7 \pm 0,21$ & $0,6 \pm 0,01$ & $0,9 \pm 0,14$ & 0,24 & $2,8 * 10^{-3}$ & 0,97 \\
\hline ХС ЛПВП, ммоль/л & $1,5 \pm 0,14$ & $1,4 \pm 0,14$ & $1,3 \pm 0,13$ & 0,83 & 0,64 & 0,98 \\
\hline ХС ЛПНП, моль/л & $2,2 \pm 0,35$ & $1,5 \pm 0,12$ & $1,6 \pm 0,11$ & 0,03 & 0,1 & 0,13 \\
\hline КА, усл. ед. & $2,5 \pm 0,31$ & $1,4 \pm 0,13$ & $1,9 \pm 0,12$ & $5,2 * 10^{-4}$ & 0,1 & 0,16 \\
\hline ОХС/ХС ЛПВП, усл. ед. & $3,3 \pm 0,53$ & $2,8 \pm 0,14$ & $2,9 \pm 0,12$ & 0,23 & 0,3 & 0,32 \\
\hline ХС ЛПНП/ХС ЛПВП, усл. ед. & $1,8 \pm 0,32$ & $1,2 \pm 0,12$ & $1,6 \pm 0,17$ & 0,01 & 0,43 & 0,13 \\
\hline Глюкоза, ммоль/л & $5,2 \pm 0,27$ & $5,3 \pm 0,21$ & $5,6 \pm 0,21$ & 0,42 & 0,23 & 0,72 \\
\hline
\end{tabular}

Примечание: результаты параметрических методов обработки полученных данных представлены в виде средних величин показателей (х) и их стандартных ошибок (SE); САД - систолическое артериальное давление, BPS, mm Hg; ДАД - диастолическое артериальное давление, BPD, тm Нg; ЧCC - частота сердечных сокращений, HR, bpm; УO - ударный объем, SV, mL; OПC - общее периферическое сопротивление, TPVR, dyne ${ }^{2}$ s сm ${ }^{-5}$; ДО - дыхательный объем, TV LVV, mL; МОД - минутный объем дыхания, RO, L/min; КИО - коэффициент использования кислорода, OUQ, mL/L; ЖЕЛ - жизненная емкость легких, VLC, \%; ПОС - пиковая объемная скорость, PEF, $1 / \mathrm{s}$; MOC $25 \%$ - мгновенная объемная скорость на участке $25 \%$ от форсированного выдоха, $\mathrm{MEF}_{25 \%}, \%$; $\mathrm{MOC}_{50 \%}$ - мгновенная объемная скорость на участке $50 \%$ от форсированного выдоха, $\mathrm{MEF}_{50 \%} \%$; MOC $_{75 \%}-$ мгновенная объемная скорость на участке $75 \%$ от форсированного выдоха, $\mathrm{MEF}_{75 \%} \%$; ПЗМР - простая зрительно-моторная реакция, SVMR, msec; CЗMP - сложная зрительно-моторная реакция, CVMR, msec; Фоновый уровень $\mathrm{HbO}_{2}$ - сатурация артериальной крови на фоне, охуgen saturation $\left(\mathrm{HbO}_{2}, \%\right)$; уровень $\mathrm{HbO}_{2}$ на пике пробы Штанге - сатурация артериальной крови на пике пробы Штанге, $\mathrm{HbO}_{2}$ at peak $\mathrm{Stange}$ test, \%; уровень $\mathrm{HbO}{ }_{2}$ на пике пробы Генчи - сатурация артериальной крови на пике пробы Генчи, $\mathrm{HbO}_{2}$ at peak Genchie test, \%; OXC - oбщий холестерин, TCh, mmol/L; ТГ - триглицериды, TG, mmol/L; XC ЛПВП - холестерин липопротеидов высокой плотности, TCh HDLP, mmol/L; XC ЛПНП - холестерин липопротеидов низкой плотности, TCh LDLP, mmol/L; KA - коэффициент атерогенности, AI, arb. units; OXC/XC ЛПВП - отношение общего холестерина к холестерину липопротеидов высокой плотности, TCh/Ch HDLP, arb. units; ХC ЛПНП/ХС ЛПВП - отношение холестерина липопротеидов низкой плотности к холестерину липопротеидов высокой плотности, Ch LDLP / Ch HDLP, arb. units; глюкоза - глюкоза крови, Glucose, mmol/L. 
Скорости простой (ПЗМР) и сложной (СЗМР) сенсомоторной реакции являются показателями, отражающими текущее состояние нервной системы. В нашем случае происходит значимое уменьшение этих показателей в ряду от мигрантов-адаптантов к лицам второго поколения.

Фоновый показатель сатурации кислородом гемоглобина $\left(\mathrm{HbO}_{2}\right)$ уменьшается от мигрантов-адаптантов к лицам второго поколения. При этом отмечается рост данного параметра в период, когда происходит выполнение пробы на выдохе (Genchie) у лиц первого и второго поколения по сравнению с юношами-адаптантами. Значение наполнения кислородом артериальной крови при исполнении дыхательной пробы на вдохе (Stange) остается неизменным в ряду разных поколений.

\section{Обсуждение}

Можно говорить о том, что установленная реакция возрастания кровяного давления в начале адаптациионного периода к условиям Северо-Востока России у новоселов является, судя по всему, компенсаторным механизмом, формирующимся под воздействием пониженных температур окружающей среды. При этом у лиц второго поколения по сравнению с юношами-мигрантами статистически значимо увеличивается ударный объем, что можно характеризовать как благоприятный фактор, когда интенсификация работы сердца связана не с повышением пульса, а с увеличением сократительной функции сердечной мышщы (Victor et al., 1987).

Снижение показателей ДО и МОД от нулевого ко второму поколению говорит об оптимизировании работы системы внешнего дыхания у этих лиц, так как вентиляция легких прямым образом воздействует на величину отдачи тепла с дыханием, и наблюдаемое снижение объемов дыхания, очевидно, является проявлением функции «экономии», реализующейся, в частности, через снижение респираторных теплопотерь, происходящих в сложных условиях внешней среды (Shishkin et al., 1995). Особо следует отметить, что в ряду от нулевого ко второму поколению статистически значимо возрастает коэффициент использования кислорода, что говорит об увеличении прохождения кислорода через альвеолярно-капиллярную мембрану (Neverova, 1972) и улучшении функции транспорта кислорода во всем организме. Наблюдаемое уменьшение объемно-скоростных показателей от юношей нулевого и первого к юношам второго поколения может свидетельствовать об уменьшении напряжения в работе респираторной системы при возрастании срока проживания на Северо-Востоке.

Время простой (ПЗМР) и сложной (СЗМР) сенсомоторной реакции является интегральным маркером скорости прохождения нервного возбуждения по элементам рефлекторной дуги (Реуsаkhov, 1974). Наблюдаемая четкая картина снижения значения как простой, так и сложной реакции (увеличения скорости нервных процессов) в ряду от нулевого ко второму поколению является отражением улучшения функциональных параметров ЦНС. В целом, анализ психофизиологических показателей говорит о повышенном уровне концентрации произвольного внимания и функционального состояния центральной нервной системы при длительном нахождении в условиях Севера. В данном случае можно говорить о том, что во время адаптации к экстремальным абиотическим условиям Северо-Востока России происходит формирование популяции укорененных жителей с высоким функциональным состоянием центральной нервной системы.

При сравнении значений оксигенации артериальной крови во время дыхательных проб на вдохе и выдохе видно, что исходный уровень сатурации артериальной крови может рассматриваться в качестве четкого критерия для оценки стадии адаптации к экстремальным природно-климатическим факторам Магаданской области. Статистически значимое понижение показателя $\mathrm{HbO}_{2}$ в ряду «нулевое - первое - второе» поколение, по-видимому, связано со снижением чувствительности дыхательного центра к концентрации углекислого газа.

При анализе биохимических характеристик крови установлено, что в выборках обследованных юношей ни одна из характе- ристик не превышала границ референтных уровней (Prophylaxis, diagnostics, 2004). Анализ липидного состава крови показал, что имеются некоторые различия в уровнях общего холестерина, холестерина липопротеидов низкой плотности и триглицеридов крови. Наивысшие показатели содержания общего холестерина в крови отмечены в группе юношей - мигрантов-адаптантов с непродолжительным сроком нахождения на территории Магаданской области. У представителей нулевого и второго поколений содержание триглицеридов в крови было статистически значимо выше, чем у представителей первого поколения. Полученные данные свидетельствуют о том, что наивысшая величина ХС ЛПНП была обнаружена у юношей-мигрантов. Статистически значимых различий по среднему уровню ХС ЛПВП у юношей трех групп в наших исследованиях не выявлено. Оптимальный уровень ЛППП имеет различные положительные эффекты, такие как антиоксидантная, антиагрегантная и антикоагулянтная функция (Kontush and Chapman, 2010; Chung et al., 2015).

Самые высокие показатели коэффициента атерогенности имели юноши с наименьшим стажем проживания (мигранты) в Магаданской области. В соответствии с использованием маркеров атерогенного потенциала липидного профиля, где рост соотношения $\mathrm{OXC/ХС} \mathrm{ЛПВП} \mathrm{более} 5$ усл. ед. и величина расчетного показателя ХС ЛПНП/ХС ЛПВП более 3,3 усл. ед. свидетельствовали о нарушении липидного профиля, ассоциированного с возрастанием риска развития атеросклероза; в наших исследованиях выявлено, что все юноши в среднем имели более низкие значения данных индексов.

Оценка углеводного обмена проведена путем определения уровня глюкозы в периферической крови натощак. Концентрация глюкозы является очень важной характеристикой внутренней среды организма. Ее уровень в кровяном русле при различных состояниях колеблется в границах 3,25-5,60 ммоль/л. Поддержание постоянства гликемии в крови является результатом работы углеводного обмена, а выход за рамки указанного диапазона говорит либо о нарушениях в работе регуляторных механизмов, либо свидетельствует о перестройке энергетического обмена (Panin, 1978). Среднее значение концентрации глюкозы в сыворотке крови у юношей варьировало от 5,2 до 5,6 ммоль/л. Полученные в нашем исследовании величины находились на верхнем уровне референтной границы для глюкозы, при отсутствии каких-либо значимых различий. Повышенное содержание в крови глюкозы в молодом возрасте может служить основой будущего развития целого ряда сердечно-сосудистых заболеваний, включая диабет второго типа и связанные с ним тяжелые осложнения complications (Porkka et al., 1994; Srinivasan et al., 1996; Juonala et al., 2011).

Полученные нами результаты также позволили выявить степень влияния продолжительности нахождения в условиях СевероВостока России на биохимический профиль адаптантов. Наши данные убедительно свидетельствуют, что у мигрантов Севера с непродолжительным периодом нахождения в экстремальных климато-географических условиях отмечается наибольший процент отклонений в липидном профиле с повышением индекса атерогенности, что согласуется с данными Krivoshapkina (2010).

\section{Заключение}

Установленный нами вектор функциональных перестроек физиологических систем мигрантов-адаптантов, а также различных поколений уроженцев из числа европеоидов-северян позволяет констатировать тот факт, что в текущих условиях Северо-Востока России происходит формирование нового типа популяции жителей Магаданской области, в отношении которой можно говорить об оптимизации значений в ряду от нулевого ко второму поколению проживания на Севере и которую можно обозначить как укорененные лица. У лиц с наибольшим стажем проживания на Севере наблюдается снижение артериального давления и повышение эффективности работы сердечной мышщы, уменьшение напряжения в работе респираторной системы при синхронном снижении респираторных теплопотерь, а также повышение функ- 
ционального уровня центральной нервной системы. В процессе проживания в сложных климатических условиях Северо-Востока России происходит формирование особенного регионального состояния метаболического профиля, характеризующегося сниженными концентрациями показателей липидного обмена и увеличенным содержанием глюкозы в крови, что, по-видимому, связано с изменением типа питания современного жителя города.

Юноши второго поколения, имеющие максимальный стаж проживания на территории Северо-Востока, характеризуются оптимальными показателями, необходимыми для эффективного адаптивного ответа на сложные климато-экологические условия среды, а также сохранения наилучшего режима функционирования различных систем организма.

\section{References}

Borovikov, V. P. (2003). Statistica. Iskusstvo analiza dannykh na kompyutere: dlya professionalov [Statistica. The art of analyzing data on a computer: for professionals]. Piter, Saint Petersburg (in Russian).

Chung, D. W., Chen, J., Ling, M., Fu, X., Blevins, T., Parsons, S., Le, J., Harris, J., Martin, T. R., Konkle, B. A., Zheng, Y., \& Lopez, J. A. (2015). High density lipoprotein modulates thrombosis by preventing von Willebrand factor selfassociation and subsequent platelet adhesion. Blood, 127, 637-645.

Denisov, V. N., Babenko, A. I., \& Trufakin, V. A. (2003). Demograficheskie problemy okhrany zdorovya naseleniya Sibiri [Demographical problems in Siberia's population health care]. Vestnik Mezhregionalnoy Assotsiatsii Zdravookhranenie Sibiri, 1, 5-8 (in Russian).

Expert panel on detection, evaluation and treatment of high blood cholestrol in adults. Executive summary of the third report of the National Cholesterol Education Program (NCEP) expert panel on detection, evaluation and treatment of high blood cholestrol in adults (Adult Treatment Panel III) (2001). The Journal of the American Medical Association, 285, 2486-2497.

Irazusta, I., Hoyos, J., Irazusta, F., Ruiz, E., \& Diaz, J. (2007). Increased cardiovascular risk associated with poor nutritional habits in first-year university students. Nutrition Research, 27, 387-394.

Juonala, M., Magnussen, C. G., Berenson, G. S., Venn, A., Burns, T. L., Sabin, M. A., Srinivasan, S. R., Patricia, S. R., Davis, H., Chen, W., Sun, C., Cheung, M., Viikari, S. A., Dwyer, T., \& Raitakari, O. T. (2011). Childhood adiposity, adult adiposity, and cardiovascular risk factors. The New England Journal of Medicine, 365, 1876-1885.

Kalichman, L., Korostishevsky, M., Batsevich, V., \& Kobyliansky, E. (2011). Hand osteoarthritis in longevity populations. Aging Clinical and Experimental Research, 23(5-6), 457-462.

Khadilkar, A., Mandlik, R., Chiplonkar, S., Khadilkar, V., Ekbote, V., \& Patwardhan, V. (2015). Reference centile curves for triceps skinfold thickness for Indian children aged 5 to 17 years and cut offs for predicting risk of childhood hypertension: A multi-centric study. Indian Pediatrics, 52(8), 675-680.

Kontush, A., \& Chapman, M. J. (2010). Antiatherogenic function of HDL particle subpopulations: Focus on antioxidative activities. Current Opinion in Lipidology, 21, 312-318.
Krivoshapkina, Z. N. (2010). Biokhimicheskiy spektr syvorotki krovi kak otrazhenie adaptivnykh metabolicheskikh protsessov u zhiteley vysokikh shirot (na primere Yakutii) [Blood serum biochemical spectrum as reflection of adaptive metabolic processes in residents of high latitudes: Evidence from Yakutia]. Yakutsk Academy Press, Yakutsk (in Russian).

Lasker, G. W. (1969). Human biological adaptability. Science, 166, 1480-1486.

Neverova, N. P. (1972). Sostoyanie vegetativnykh funktsiy u zdorovykh lyudey v usloviyakh Kraynego Severa [State of autonomic functions in healthy people under Extreme North conditions]. Novosibirsk GMI Press, Novosibirsk (in Russian).

Oesterman, P. O., Lovstrand, K. G., Lyndberg, P. O., Lundberg, P. O., Lundquist, S., \& Muhr, C. (1981). Weekly headace periodically and effect of weather changes on headance. International Journal of Biometeorology, 25(1), 39-45.

Panin, L. Y. (1978). Energeticheskie aspekty adaptatsii [Energetic aspects of adaptation]. Medicina Press, Leningrad (in Russian).

Peysakhov, N. I. (1974). Samoregulyatsiya i tipologicheskie svoystva nervnoy sistemy [Autoregulation and typological properties of nervous system]. KGU Press, Kazan' (in Russian).

Porkka, K. V., Viikari, J. S., Taimela, S., Dahl, M., \& Akerblom, H. K. (1994). Tracking and predictiveness of serum lipid and lipoprotein measurements in childhood: a 12-year follow-up. The cardiovascular risk in young finns study. American Journal of Epidemiology, 140, 1096-1110.

Prophylaxis, diagnostics and treatment of hypertension. Russian recommendations (The second revision). (2004). Prilozhenie k zhurnalu Kardiovaskuljarnaja terapija i profilaktika [A supplement to the journal of Cardiovascular therapy and prophylaxis], 20 (in Russian).

Shershakova, Y. M. (2008). Otsenka demograficheskoy bezopasnosti Magadanskoy oblasti [Magadan region demography safety assessment]. Prostranstvennaya Ekonomika, 4, 153-165 (in Russian).

Shishkin, G. S., Petrunev, S. A., \& Preobrazhenskaya, V. K. (1995). Osobennosti ventilyatsii legkikh pri dykhanii nizkotemperaturnym vozdukhom [Specific profiles for lung ventilation at respiring low temperature air]. Fiziologiya Cheloveka, 21(2), 61-66 (in Russian).

Soulman, J., Levition, A., Slack, W., Porter, D., \& Graham, J. R. (1980). The relationship of headache occurrence to atmospheric pressure. International Journal of Biometeorology, 24(3), 213-219.

Srinivasan, S. R., Bao, W., Wattigney, W. A., \& Berenson, G. S. (1996). Adolescent overweight is associated with adult overweight and related multiple cardiovascular risk factors: The Bogalusa heart study. Metabolis, 45, 235-240.

Startseva, O. N., Belousov, V. V., Frolova, O. V., \& Gilmanov, A. J. (2007). Osobennosti nekotorykh pokazateley lipidnogo i belkovogo obmena u prishlogo naseleniya regionov Kraynego Severa [Some profiles of lipid and protein metabolism in new-coming populations of Extreme North regions]. Klinicheskaja Laboratornaja Diagnostika, 8, 22-35 (in Russian).

Victor, R. G., Seals, D. R., \& Mark, A. L. (1987). Differential control of heart rate and sympathetic nerve activity during dynamic exercise: Insight from intraneural recordings in humans. Journal of Clinical Investigation, 79(2), 508-516.

Yurev, V. V., Simakhodskyi, A. S., \& Voronovich, N. N. (2003). Rost i razvitie rebenka [Child's growth and development]. Piter, Saint Petersburg (in Russian). 